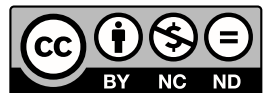

Estudos Teológicos foi licenciado com uma Licença Creative Commons Atribuição - NãoComercial - SemDerivados 3.0 Não Adaptada

http://dx.doi.org/10.22351/etv59i2.3708

\title{
A IMPortânCia dos ritos de PaSSagem na AdOLESCÊnCIA: UM ESTUDO DE CASO ${ }^{1}$
}

The importance of rites of passage in adolescence: a case study

Gisela Isolde Waechter Streck²

Resumo: O artigo traz uma reflexão sobre a importância e a pertinência dos ritos de passagem na adolescência e quer ver em que medida esses podem auxiliar adolescentes a fazerem a transição da infância para a vida adulta. A adolescência, nas sociedades ocidentais, é uma etapa preparatória para a adultez e de espera para a integração no mundo das pessoas adultas. Contardo Calligaris afirma que o problema para adolescentes é a duração dessa fase, pois a sociedade impõe uma moratória sem prazo de duração. Como se sai da adolescência? Para essa pergunta não há uma resposta precisa. Em outros tempos e em diferentes culturas havia (e ainda há) ritos de passagem, mas nos dias de hoje adolescentes não são mais ajudados a fazer a passagem por meio de ritos. Françoise Dolto afirma que adolescentes não são mais levados/as em conjunto e solidariamente de uma margem para a outra, mas devem fazer a travessia individualmente, o que pode gerar angústia, medo e solidão. Como os ritos de passagem podem contribuir para que adolescentes possam ser auxiliados/as e acompanhados/as na "travessia", quando experimentam os ritos preliminares (a separação) e os liminares (a margem), e assim serem conduzidos/as de uma margem a outra? Sobre essas questões este artigo quer refletir e trazer elementos e questionamentos. A pesquisa traz uma revisão bibliográfica e o resultado de uma pesquisa social, metodologicamente definida como estudo de caso, que apresenta dados sobre um rito de passagem oferecido para adolescentes nas comunidades luteranas.

Palavras-chave: Adolescência. Ritos de passagem. Vida adulta.

Abstract: The article reflects on the importance and relevance of rites of passage in adolescence and wants to see to what extent they can help adolescents make the transition from childhood to adulthood. Adolescence in Western societies is a preparatory stage for adulthood and waiting for adult integration into the world. Contardo Calligaris affirms that the problem for adolescents is the duration of this phase, because the society imposes a moratorium without term of duration. How do you get out of adolescence? For this question there is no precise answer. In other times and in different cultures there were (and still are) rites of passage, but nowadays adolescents are no longer helped to

1 O artigo foi recebido em 01 de junho de 2019 e aprovado em 04 de outubro de 2019 com base nas avaliações dos pareceristas ad hoc.

2 Doutora. Faculdades EST, São Leopoldo, RS. E-mail: giselastreck@gmail.com 
make the passage through rites. Françoise Dolto affirms that adolescents are no longer taken jointly and severally from one margin to the other, but must make the crossing individually, which can generate anguish, fear and loneliness. As rites of passage can help adolescents to be assisted and followed in the "crossing", when they experience the preliminary rites (the separation) and the injunctions (the margin), and thus are conducted from a margin the other? On these issues this article wants to reflect and bring elements and questions. The research brings a bibliographical review and the result of a social research, methodologically defined as a case study, which presents data on a rite of passage offered for adolescents in Lutheran communities.

Keywords: Adolescence. Rites of passage. Adult life.

\section{Introdução}

A criança, até o final do século XIX, iniciava sua vida no mundo do trabalho a partir dos sete anos e até o início da puberdade. Na sociedade ocidental, a partir do século XX, essa realidade se modifica gradativamente. Com o advento da era industrial, é cada vez maior a exigência por capacitação e formação especializada, o que leva um contingente cada vez maior de crianças a permanecer mais tempo nas escolas ou buscar algum tipo de instrução.

A nova realidade, a partir do século $\mathrm{XX}$, contribuiu para que, no ocidente, a incorporação das crianças no trabalho e sua integração na sociedade das pessoas adultas se prolongassem cada vez mais, possibilitando o surgimento de um grupo social peculiar, a adolescência. Essa realidade, no entanto, não é a mesma em todas as culturas. Em outras sociedades as crianças são introduzidas na vida adulta, com todas as implicações e responsabilidades decorrentes, por meio de rituais de iniciação bem definidos. ${ }^{3}$

Na sociedade ocidental, na mesma medida em que se consolida a adolescência como uma fase da vida, os ritos de passagem, como rituais de ingresso na vida adulta, se fragilizam e perdem sua importância. A questão que se apresenta é como se dá esta transição e quais as consequências advindas do fato de esses rituais, em grande medida, perderem sua importância e mesmo assim continuar sendo necessário, de alguma forma, marcar essa passagem de uma fase para outra no curso da vida.

\section{Adolescência e ingresso no mundo adulto}

Erikson afirma que uma das tarefas mais importantes da adolescência é a elaboração da identidade. Esse processo tem um aspecto pessoal e social. Assim, a formação da identidade é "um processo 'localizado' no âmago do indivíduo e também no núcleo central da sua cultura coletiva", ou seja, há uma relação entre o "núcleo cen-

3 PALÁCIOS, Jesus. O que é a adolescência. In: COLL, César; PALACIOS, Jesús; MARCHESI, Alvaro (Orgs.). Desenvolvimento psicológico e educação: psicologia evolutiva. Trad. Marcos A. G. Domingues. Porto Alegre: Artes Médicas, 1995. v. 1, p. 263-265 
tral da cultura" e a formação da identidade. ${ }^{4} \mathrm{O}$ indivíduo (o eu) necessita do ambiente social (a cultura, os outros) para estruturar sua identidade. Erikson afirma:

[...] o indivíduo se julga a si próprio à luz daquilo que percebe ser a maneira como os outros o julgam, em comparação com eles próprios e com uma tipologia que é significativa para eles; enquanto que ele julga a maneira como eles o julgam, à luz do modo como se percebe a si próprio em comparação com os demais e com os tipos que se tornaram importantes para ele $^{5}$.

Para Erikson o termo alemão "Umwelt" é o que melhor descreve aquilo que define como ambiente social: aquilo "que nos cerca, mas que também está em nós". Esse processo de elaboração da identidade é como olhar num espelho, onde a pessoa adolescente vê refletida a própria imagem e aquela que imagina que "os outros" tenham dela.

Para Calligaris, o espelho é um lugar "tentador" e ao mesmo tempo "perigoso": "[...] me vejo bonito ou desejável, se tenho razões de acreditar que os outros gostam de mim ou me desejam. Vejo, em suma, o que imagino que os outros vejam"?. No entanto, esse espelho está muitas vezes vazio, pois falta ao indivíduo tanto o "olhar apaixonado que ele merecia quando criança" como também a autorização para se considerar adulto e ingressar no mundo das pessoas adultas. $\mathrm{O}$ "espelho vazio" pode trazer baixa autoestima, depressão e tentativas de suicídio, ou seja, a adolescência é uma fase da vida também marcada pela insegurança. ${ }^{8}$

Erikson afirma que o indivíduo não necessita apenas de um "mero reconhecimento de uma realização individual" e sim "que lhe respondam e confiram status e função como uma pessoa cujo crescimento e transformação graduais fazem sentido para aqueles que começaram fazendo sentido para ele". Assim, a tarefa que a adolescência impõe ao indivíduo, de elaborar sua identidade, fazer escolhas e tomar decisões "para toda a vida", é uma tarefa "formidável" que requer um grande esforço da pessoa e da sociedade. ${ }^{9}$ Erikson empresta o postulado de "período de latência" que a psicanálise reconheceu para a fase de espera anterior à puberdade e afirma que também na adolescência a sociedade oferece aos indivíduos um período de espera e de "livre experimentação de papéis", que chamou de moratória psicossocial.

Uma moratória é um período de espera concedido a alguém que não está apto para satisfazer uma obrigação ou imposto a alguém que deveria fixar-se um prazo de tempo. Assim, por moratória psicossocial entendemos um compasso de espera nos compromissos adultos e, no entanto, não se trata apenas de uma espera. É um período que se

\footnotetext{
ERIKSON, Erik. Identidade, Juventude e Crise. Rio de Janeiro: Zahar, 1976. p. 21.

ERIKSON, 1976, p. 21.

ERIKSON, 1976, p. 22-23.

CALLIGARIS, Contardo. A adolescência. 2. ed. São Paulo: Publifolha, 2009. p. 25.

CALLIGARIS, 2009, p. 25.

9 ERIKSON, 1976, p. 156.
} 
caracteriza por uma tolerância seletiva por parte da sociedade e uma atividade lúdica por parte do jovem. ${ }^{10}$

Esse tempo de moratória, que as próprias sociedades e culturas oferecem aos seus membros, varia de acordo com os valores dos diferentes grupos sociais e culturais e pode ser tanto um período de aprendizado, experimentação e "aventura", como também de "patologias" e "delinquências". Erikson aponta a delinquência juvenil como uma moratória psicossocial, de certa forma já institucionalizada por algumas sociedades, que pode ser um período normal de transição entre a infância e a vida adulta, ou redundar em fracasso, quando não há volta e "o indivíduo é definido cedo demais e engajou-se porque as circunstâncias ou, de fato, as autonomias o comprometeram"11.

Para Calligaris, o período de moratória é a própria fase da adolescência, visto que o ingresso na vida adulta ficou postergado, por "uns 10 anos". Não há autorização das pessoas adultas, mesmo que adolescentes se sintam capazes. "É com a modernidade tardia (com o século que mal acabou) que essa moratória se instaura, se prolonga e se torna enfim mais uma idade da vida." 12

Calligaris define a pessoa adolescente como alguém:

1. " [...] que teve tempo de assimilar os valores mais banais e bem compartilhados na comunidade $[\ldots]$

2. cujo corpo chegou à maturação necessária para que ele possa efetiva e eficazmente se consagrar às tarefas que lhe são apontadas por estes valores, competindo de igual para igual com todo mundo;

3. para quem, nesse exato momento, a comunidade impõe uma moratória"13.

Assim, conclui-se, de acordo com Calligaris:

[...] há um sujeito capaz, instruído e treinado por mil caminhos - pela escola, pelos pais, pela mídia - para adotar os ideais da comunidade. Ele torna-se adolescente quando, apesar de seu corpo e seu espírito estarem prontos para a competição, não é reconhecido como adulto ${ }^{14}$.

Adolescentes se julgam capazes de realizar o que a sociedade espera, mas a tão sonhada autonomia, que juntamente com a independência são "valores essenciais" na sociedade de hoje, "é reprimida, deixada para mais tarde"15.

Calligaris pergunta pela duração da adolescência e afirma que a questão principal não é quando inicia, mas como o indivíduo sai dessa fase da vida. O que é necessário ser ou fazer para ingressar, e ser aceito, no mundo das pessoas adultas? Em outras culturas

${ }^{10}$ ERIKSON, 1976, p. 157.

${ }^{11}$ ERIKSON, 1976, p. 15.

${ }^{12}$ CALLIGARIS, 2009, p. 16.

${ }^{13}$ CALLIGARIS, 2009, p. 15.

${ }^{14}$ CALLIGARIS, 2009, p. 15.

15 CALLIGARIS, 2009, p. 15. 
há rituais de iniciação na vida adulta e mesmo sendo difíceis, muitas vezes dolorosos, ainda assim "serão sempre mais suportáveis do que a indefinida moratória moderna"

Machado Pais aponta outros fatores que dificultam o processo de entrada na vida adulta e fala numa "reversibilidade", quando pessoas jovens enfrentam o desemprego, $\mathrm{o}$ divórcio e a necessidade de voltar para a casa dos pais, por não conseguirem se manter financeiramente. Assim propõe "o conceito de yoyogeneização da condição juvenil" "17.

Dolto, ao falar das culturas mais antigas, afirma que os ritos de iniciação eram formas "de proteger todos os seus membros e assim, encontrava o meio de anexar ao clã todos os jovens"18. Duas questões são importantes nesse sentido: a importância que se dá às pessoas jovens e à sua integração ao clã e o fato de esse ritual ser também um ato social, realizado pelo grupo: "Essas provas coletivas ajudavam os jovens a se libertarem do sentimento de culpa transgressiva que toma conta deles, pois a passagem feita sozinho, sem apoio, é vivida como uma transgressão"19.

\section{Os ritos de passagem e a adolescência}

O curso da vida é marcado por ritos de passagem, tais como o nascimento, o casamento, a aposentadoria, a morte. Também há ritos de passagem na vida cotidiana, tais como da rua para a casa, de uma casa para outra, a entrada na escola, na faculdade, no emprego; e ritos de passagem religiosos como batismo, comunhão. Nesse sentido, van Gennep afirma:

É o próprio fato de viver que exige as passagens sucessivas de uma sociedade especial a outra e de uma situação social a outra, de tal modo que a vida individual consiste em uma sucessão de etapas, tendo por término e começo conjuntos da mesma natureza, a saber, nascimento, puberdade social, casamento, paternidade, progressão de classe, especialização de ocupação, morte ${ }^{20}$.

Os ritos que marcam a passagem de uma fase para outra têm a função de trazer segurança, auxiliar na transição: "Estas modificações do estado não deixam de perturbar a vida social e a vida individual. Certo número de ritos de passagem destina-se a reduzir os efeitos nocivos de tais mudanças" ${ }^{\text {"21 }}$. Arnold van Gennep faz uma categorização dos ritos de passagem: "Dada à importância dessas passagens acredito ser legítimo distinguir uma categoria especial de Ritos de passagem, que se decompõem, quando submetidos à análise, em Ritos de separação, Ritos de margem, e Ritos de agregação" 22 . O autor faz também um desdobramento dessas categorias e afirma:

${ }^{16}$ CALLIGARIS, 2009, p. 20.

${ }^{17}$ PAIS, José Machado. A juventude como fase de vida: dos ritos de passagem aos ritos de impasse. Saúde Soc. São Paulo, v. 18, n. 3, 2009. p. 373.

${ }_{18}^{18}$ DOLTO, Françoise. A causa dos adolescentes. Aparecida/SP: Idéias \&.Letras, 2004. p. 92-93.

${ }_{19}$ DOLTO, 2004, p. 92-93.

${ }^{20}$ GENNEP, Arnold van. Os ritos de passagem. Petrópolis: Vozes, 1977. p. 26-27.

${ }^{21}$ GENNEP, 1977, p. 31.

22 GENNEP, 1977, p. 31. 
"[...] o esquema completo dos ritos de passagem admite em teoria ritos preliminares (separação), liminares (margem) e pós-liminares (agregação) [...]"23.

Terrin, citado por Meira, apresenta as três categorias como condição e ainda aponta para dois focos: "a condição precedente, o período de marginalidade e a inserção na nova condição. [...] dois outros focos nos estudos dos ritos de passagem: como uma resposta adaptativa - os indivíduos são obrigados a mudar de posição dentro de um sistema - e como mudança do plano individual para o coletivo" ${ }^{24}$. Esses dois focos são importantes para o entendimento a respeito dos ritos, na medida em que remetem para a questão da passagem de um estado para outro e do individual para o coletivo.

Meira baseia-se em Benveniste para buscar uma definição de rito a partir da palavra latina ritus, que tem o significado de "ordem estabelecida", e da palavra grega artýs, que significa "prescrição, decreto"; já a raiz antiga ar pode ser definida por "modo de ser, disposição organizada e harmônica das partes no todo". As palavras "arte, rito e ritual" assim remetem a ideia de "harmonia restauradora". Outra possibilidade de definir rito diz respeito ao sentido da raiz $r i$, " $[. .$.$] - escorrer - liga-se ao sig-$ nificado que tem as palavras ritmo, rima, rio, sugerindo o fluir ordenado de palavras, da música, d'água. Pode-se apresentar o rito entendido como o fluir de movimento e repouso $[\ldots]]^{\prime 25}$. Também aqui a compreensão sobre o rito sugere movimento e transição. Meira afirma: "O rito faz referência a uma ação realizada em determinado tempo e espaço, diferente das ações da vida cotidiana, distinta do comportamento comum"26.

A adolescência pode ser definida como uma fase de transição entre a infância e a adultez; é movimento, um momento de iniciação, de entrada numa nova fase do ciclo da vida e uma preparação para a maturidade e início da vida adulta. Assim, na adolescência a pessoa experimenta ritos de separação ou preliminares, quando busca a independência de seu núcleo familiar e sua autonomia, elabora sua própria identidade, toma decisões sobre seu futuro e se responsabiliza pelas escolhas que faz. Por outro lado, a adolescência também é um tempo de moratória, como os ritos liminares, de margem, ou seja, de espera e de preparação para ingressar numa nova etapa do curso de vida. ${ }^{27}$

Essa transição de uma fase da vida para outra traz ganhos, mas também pode ser um tempo de angústia e insegurança, por causa das mudanças que acontecem, tanto nos aspectos biológicos como psicológicos e sociais. Aberastury fala em sentimento de luto no início da adolescência pela perda do corpo infantil, pela perda dos pais da infância e pela perda do lugar social..$^{28}$

Assim, na adolescência o ser humano vive tanto os ritos preliminares de separação, como também os ritos liminares, ou os assim chamados ritos de margem. Arnold van Gennep afirma que esses ritos de margem podem se estender por um tempo

${ }^{23}$ GENNEP, 1977, p. 31.

${ }^{24}$ TERRIN, 2004, p. 100 apud MEIRA, Mônica Birchler Vanzella. Sobre estruturas etárias e ritos de passagem. Ponto-e-Virgula Revista de Ciências Sociais, São Paulo, v. 5, $1^{\circ}$ sem. 2009. p. 189.

${ }^{25}$ BENVENISTE, 1969 apud MEIRA, 2009, p. 187-188.

${ }^{26}$ MEIRA, 2009, p. 188.

${ }^{27}$ GENNEP, 1977, p. 31.

${ }^{28}$ ABERASTURY, A. et al. Adolescência normal. 2. ed. Porto Alegre: Artes Médicas, 1992. p. 23. 
maior, chegando essa fase a se "constituir como etapa autônoma"29. A adolescência é uma situação de margem: houve uma separação da fase anterior, da infância, mas ainda não há uma agregação. Ainda há ritos de passagem para a entrada na vida adulta nas sociedades de hoje?

Dolto afirma que, se os ritos de passagem não existem mais nas sociedades de hoje, um projeto, ou um sonho que "vai se realizando sem preocupação com o futuro" pode ser uma forma de adolescentes realizarem essa "passagem". A autora denomina de "evasão" essa fuga para espaços e tempos diferentes daqueles que adolescentes viveram até então, na sua infância. ${ }^{30} \mathrm{Na}$ realidade de hoje, algumas questões, entre outras, podem ser definidas como problemáticas para que adolescentes possam fazer a "travessia", a passagem para a vida adulta, de tal modo que sejam agregados e se sintam inseridos no mundo adulto.

Machado Pais fala numa "situação de impasse" vivida por jovens, pois em muitos casos até conseguem fazer a "passagem simbólica da juventude para a idade adulta", mas não conseguem manter essa condição. Muitos fatores contribuem para essa "situação de impasse" vivida por adolescentes e jovens, como o desemprego e a instabilidade econômica, a dificuldade de se tornarem independentes e iniciarem uma vida familiar própria. ${ }^{31}$ Para Machado Pais, mesmo que, na realidade de hoje, as fases do curso da vida não sejam tão claramente definidas, ainda assim “[...] continuam a ser valorizados determinados marcadores de passagem entre as várias fases de vida" 32 . Por outro lado, como os ritos de passagem perderam sua importância, adolescentes e jovens são, cada vez mais, instigados e instigadas e até compelidos e compelidas a assumirem individualmente a tarefa de fazer essa passagem.

Para Lipovetsky, a individualização é uma das características da realidade de hoje: "O ideal moderno de subordinação do indivíduo a regras racionais coletivas foi pulverizado, o processo de personalização promoveu e encarnou maciçamente um valor fundamental: o da realização pessoal" ${ }^{33}$. Nesse sentido, à ausência dos ritos de agregação na adolescência ou à pouca importância que têm na realidade de hoje soma-se a vivência solitária e individual, em detrimento da vida grupal. Assim também a transição para a vida adulta é feita individualmente, como afirma Lipovetsky: "Hoje em dia vivemos para nós mesmos, sem nos preocuparmos com as nossas tradições e com nossa posteridade: o sentido histórico foi abandonado, da mesma maneira que os valores e as instituições sociais" ${ }^{34}$.

${ }^{29}$ GENNEP, 1977, p. 31.

${ }^{30}$ DOLTO, 2004, p. 94.

31 PAIS, 2009, p. 374.

32 PAIS, 2009, p. 374.

33 LIPOVETSKY, Gilles. A era do vazio; ensaios sobre o individualismo contemporâneo. Barueri, SP: Manole, 2005. p. XVII.

${ }^{34}$ LIPOVETSKY, 2005, p. 33. 


\section{Fragilização dos ritos de passagem - um estudo de caso}

Em outros tempos e em diferentes culturas havia (e ainda há) ritos de passagem, mas nos dias de hoje, adolescentes não são mais ajudados e ajudadas a fazer a passagem por meio de ritos. Françoise Dolto afirma que pessoas adolescentes, entregues a si mesmas, não são mais levadas em conjunto e solidariamente de uma margem para a outra, mas elas mesmas devem fazer a "travessia" individualmente, o que pode gerar angústia, medo e solidão. ${ }^{35}$ Nesse sentido, foi realizada uma pesquisa social ${ }^{36}$ que teve como objetivo investigar a importância e a pertinência de ritos de passagem ainda hoje oferecidos como possibilidades para que pessoas adolescentes possam ser auxiliadas e acompanhadas na "travessia", quando experimentam os ritos preliminares (a separação), os liminares (a margem), e os pós-liminares - a agregação. Para tanto se buscou um rito de passagem oferecido nas comunidades da Igreja Evangélica de Confissão Luterana no Brasil - IECLB, o Ensino Confirmatório e a Confirmação do Batismo. As comunidades religiosas oferecem ritos de passagem aos seus membros adolescentes, com idade entre 12 a 15 anos, como uma maneira de marcar o ingresso desses na vida comunitária como membros adultos. Nas comunidades luteranas, o assim chamado Ensino Confirmatório é um espaço de formação e de aprendizado na fé, e uma preparação para a Confirmação do Batismo. $\mathrm{O}$ ato da Confirmação é entendido como uma resposta pessoal ao Batismo realizado na infância. Para que esse passo possa ser dado, é necessário um tempo de preparo e aprendizado, que nas comunidades luteranas corresponde ao Ensino Confirmatório. Assim as principais questões relacionadas à fé são ensinadas, para que o lugar que lhes cabe como membros adultos da comunidade religiosa possa ser assumido. ${ }^{37}$

Nesse sentido, percebe-se um processo de ritualização da separação quando pessoas adolescentes não são mais consideradas crianças, mas aptas a assumirem seu papel como membros adultos na comunidade; de margem, que se traduz no período de preparação e aprendizado; e de agregação, quando na Confirmação, a pessoa adolescente confirma e aceita pessoalmente seu Batismo perante a comunidade, num momento de culto, quando lhe é perguntado sobre sua decisão e se espera sua resposta positiva. Meira relaciona essa resposta com responsabilidade: "Responsabilidade é a junção de responsável e idade, significando qualidade ou condição de responsável, ou aquele que responde pelos próprios atos ou pelos de outrem"38. Assim o rito tem a função de mudança de status, sendo que a partir desse momento a pessoa é aceita como membro

35 DOLTO, 2004.

${ }^{36}$ O projeto de Pesquisa foi aprovado pelo Comitê de Ética em Pesquisa da Faculdades EST, São Leopoldo, RS. Registro na Plataforma Brasil: CAAE $n^{\circ}$ : 69089417.9.0000.5314. A coleta de dados iniciou-se somente após a assinatura do TCLE pelas pessoas que participaram da pesquisa. No caso do grupo de adolescentes, o TCLE foi assinado pelas pessoas responsáveis.

${ }^{37}$ NOSSA fé, nossa vida. Disponível em: < http://www.luteranos.com.br/conteudo/nossa-fe-nossa-vida-aconfirmacao $>$. Acesso em: 23 set. 2015.

38 P. 193 
adulto. A questão principal é se esse rito efetivamente insere as pessoas adolescentes nas suas comunidades e se essas recebem esse novo status de membros adultos.

A pesquisa caracteriza-se metodologicamente como um estudo de caso. Yin considera o estudo de caso como uma estratégia de pesquisa, ou seja, "compreende um método que abrange tudo", desde planejamento da pesquisa, definição das técnicas de coleta de dados e análise dos mesmos. O critério utilizado para selecionar a unidade de análise relaciona-se diretamente com o tipo de contexto que possibilita uma prática social específica, que envolve o público e seu objeto de pesquisa. ${ }^{39}$ Young e Schmid afirmam que um estudo de caso "pode ser considerado como um fato que descreve qualquer fase ou o processo da vida inteira de uma unidade - em suas diversas inter-relações dentro de seu cenário cultural -, seja essa unidade uma pessoa, uma família, um grupo social, uma instituição social, uma comunidade, ou uma nação" ${ }^{40}$.

A unidade pesquisada foi uma comunidade da IECLB situada num contexto urbano, no estado do Rio Grande do Sul. Foram entregues questionários com perguntas abertas e fechadas para 14 adolescentes, sendo nove meninas e cinco meninos; outro questionário para familiares de adolescentes e um terceiro para as lideranças da comunidade, neste caso para oito pessoas.

A sistematização dos dados foi realizada por meio da utilização do método estatístico, mesmo que a pesquisa seja qualitativa, conforme Young e Schmid. ${ }^{41}$ Esse procedimento foi usado para mapear as perguntas fechadas dos questionários, que foram pré-codificados nas perguntas fechadas. Nas questões abertas, a codificação foi feita posteriormente, a partir das categorias que foram estabelecidas, tomando por base as respostas. A sistematização dos dados coletados pelos demais instrumentos de pesquisa foram codificados e analisados a partir das categorias estabelecidas pelos referenciais teóricos.

Os resultados ${ }^{42}$ mostraram que o Ensino Confirmatório/Confirmação não é mais um rito de passagem que insere adolescentes na comunidade religiosa como membros adultos. Isso é corroborado pela seguinte constatação: dos/as 14 adolescentes que responderam ao questionário, 11 estão com 12 anos, ou seja, de acordo com o Estatuto da Criança e do Adolescente (ECA), recém ingressaram na adolescência. A partir da pergunta $\mathrm{n}^{\mathrm{o}} 15^{43}$ do questionário para adolescentes, é possível ver que esses e essas não percebem o rito como uma mudança de status na sua comunidade religiosa.

Do total de respostas, dez adolescentes disseram que não haverá mudanças. Dessas dez respostas, cinco não deram outras explicações sobre os motivos de uma

\footnotetext{
39 YIN, Robert K. Estudo de caso: planejamento e métodos. 3. ed. Porto Alegre: Bookman, 2005. p. 33.

${ }^{40}$ YOUNG, Pauline V.; SCHMID, C. Métodos científicos de investigación social: introducción a los fundamentos, contenido, método, principios y análisis de las investigaciones sociales. 2. ed. México, 1960. p. 272.

41 YOUNG; SCHMID, 1960.

${ }^{42}$ Todos os dados trazidos a seguir foram retirados do Relatório de Pesquisa do projeto de pesquisa "Os ritos de passagem e a religiosidade na adolescência: desafios para a "travessia" de adolescentes e sua inserção no "mundo adulto", que foi realizado em 2017. O Relatório Final de Pesquisa está cadastrado na Plataforma Brasil.

43 Depois da Confirmação, você imagina que as pessoas adultas da comunidade mudarão sua forma de tratá-lo/a?
} 
não mudança de tratamento. Uma pessoa respondeu que não haverá mudanças porque sempre foi tratada com respeito; outra respondeu "somos todos iguais"; e outra respondeu na mesma direção: "Todos somos iguais na comunidade e perante Deus, não importa a idade". Outra resposta para o "não" foi: "Porque muitos até nem sabem de muitos assuntos que aprendemos durante o Ensino Confirmatório". A única resposta que se aproxima de alguma maneira com a possibilidade de uma mudança de status foi de uma adolescente de 14 anos: "Não mudará em nada somente posso ter mais responsabilidades dentro da comunidade que decidi participar, em fazer a Confirmação".

Outras três pessoas responderam "sim", e suas explicações foram: "Porque estou conhecendo um pouco mais da Palavra de Deus"; "Sim, pois eu já mudei um pouco depois que entrei passei a respeitar mais as pessoas". E um adolescente de 12 anos respondeu que sim, vai mudar, pois não vai mais precisar da ajuda dos pais quando crescer. A pessoa que disse "talvez" afirmou que depende do pensamento da maioria das pessoas. A questão que chama atenção nessas respostas é o fato de elas estarem relacionadas a ações das próprias pessoas adolescentes, quando a pergunta foi sobre a mudança de tratamento aferido pelas pessoas adultas aos e às adolescentes.

No questionário para as oito lideranças da comunidade, a questão $\mathrm{n}^{\circ} 8$ perguntou: "Em sua opinião, o/a confirmando/a continuará participando da comunidade depois da Confirmação?". Sete pessoas responderam "Sim" e duas pessoas não deram explicações para sua resposta. Duas afirmam que sim, que a maioria das pessoas adolescentes já participa das atividades da comunidade, frequentando grupos específicos para sua faixa etária; e três pessoas responderam sim, mas afirmaram que a grande maioria ou somente uma parte se mantém inserida na comunidade e participando ativamente. A oitava resposta é mais precisa: somente um terço dos confirmandos e confirmandas continua frequentando as atividades oferecidas. A mesma pergunta foi feita aos familiares dos e das adolescentes e todas as respostas foram "Sim". As explicações foram em duas direções: já participam de grupos de jovens; há um incentivo e uma expectativa de familiares no sentido de que filhos e filhas se insiram nas atividades oferecidas para esse grupo.

Para esses dois públicos foi perguntado a respeito das atividades que a comunidade oferece ao seu grupo de adolescentes. A maioria apontou para o grupo de jovens existente na comunidade e para os cultos. Chama a atenção que também foram mencionadas atividades mais direcionadas às crianças, como o Culto Infantil, encontros de crianças, Dia do Pijama. Uma familiar e duas pessoas da liderança não responderam a questão. Uma familiar respondeu: "Ele não costuma participar muito por escolha dele". Para as lideranças também foi perguntado a respeito do espaço que adolescentes e jovens deveriam ocupar na comunidade, e seis pessoas afirmaram que deveriam participar das atividades da comunidade, como cultos, encontros, e se inserirem em diferentes setores da comunidade e gradativamente assumir cargos de direção. Uma pessoa afirmou que deveriam se inserir nos grupos de jovens da comunidade e outra afirmou: "O problema é conseguir trazer para a comunidade".

Por outro lado, quando perguntados sobre o seu lugar na comunidade, um adolescente respondeu que não sabe e uma adolescente não respondeu. Sete adolescentes apontaram o culto, o grupo de jovens e outras atividades que são oferecidas na comu- 
nidade. Quatro adolescentes fizeram referência ao fato de se tornarem membros ou integrantes da comunidade "como muitos outros". Aqui chama a atenção o fato de, para a maioria, este ser o momento do ingresso na comunidade, como se antes não houvesse um sentimento de pertencimento; e numa segunda constatação, esse ingresso colocá-los efetivamente como adolescentes na comunidade e não como membros adultos. Um adolescente respondeu que será legal e sempre respeitará a Deus.

Uma questão que perpassa toda a pesquisa, nas respostas dos três grupos, é a vinculação entre Ensino Confirmatório e educação, neste caso, a educação cristã. Duas questões são importantes nessa vinculação. A primeira diz respeito à ideia de que a Confirmação, por ser a finalização do todo o processo, pode ser vista mais como uma "formatura ou despedida da comunidade", de acordo com os estudos realizados por Wachs ${ }^{44}$, que fez sua pesquisa sobre o mesmo rito, que é realizado com adolescentes com idade entre 12 a 15 anos, nas comunidades da IECLB. Assim, o rito de agregação à comunidade é dificultado, como é possível perceber em respostas dadas por familiares e pelas lideranças da comunidade. Se as pessoas adolescentes efetivamente não ingressam nos grupos e deixam de frequentar os cultos e os espaços que a comunidade religiosa destina a elas, estabelece-se um afastamento e perde-se a oportunidade de acompanhar solidariamente a "travessia" que adolescentes farão até o ingresso no mundo das pessoas adultas.

Uma segunda constatação está relacionada às respostas que adolescentes deram para a pergunta $n^{\circ} 10$ : Há ligação entre os temas estudados e o seu dia a dia? Seis adolescentes responderam que não; cinco adolescentes responderam que sim e enumeraram os temas tratados nos encontros: mandamentos, Santa Ceia, Batismo, Confirmação, fé no Deus libertador, libertação de escravos, êxodo, Martim Lutero. Todos os assuntos são relativos a temas teológicos e são tradicionalmente tratados no Ensino Confirmatório como instrução para que adolescentes apreendam os conteúdos da confessionalidade luterana. Outras respostas vão mais ao encontro de valores e comportamentos: fazer o bem, respeito mútuo, não tirar proveito das situações. Um adolescente não enumerou temas e uma adolescente respondeu: Sim, sempre aprendemos dia a dia. Outro adolescente respondeu: "Honrar pai e mãe, na verdade os mandamentos são regras que usamos no dia a dia". Transparece aqui um ensino que cumpre sua tarefa de transmitir os ensinamentos basilares de tradição cristã e luterana para adolescentes cujas famílias são membros da comunidade religiosa. Por outro lado, há uma ausência em termos de espaço para tratar das questões do cotidiano, das angústias, das dúvidas existenciais e dos medos que adolescentes podem sentir nessa etapa do percurso da vida. Nesse sentido, as pessoas adultas da comunidade "perdem" a oportunidade de orientar e acompanhar a "travessia" de adolescentes, quando o rito de margem não oferece uma educação que leva em conta as especificidades dessa fase da vida e o rito da agregação se resume a uma cerimônia de "formatura" depois de um período de aprendizagem.

\footnotetext{
${ }^{44}$ WACHS, Manfredo Carlos. Confirmação na IECLB: Contribuições para um método. São Leopoldo: Escola Superior de Teologia, 1995. p. 66.
} 


\section{Considerações finais}

Assim, pode-se concluir que na fase da adolescência os indivíduos tanto experimentam os ritos preliminares de separação como uma situação de margem, sem que saibam ao certo como ou o que fazer para serem aceitos no mundo das pessoas adultas. A margem, como um espaço de transição, torna-se um lugar permanente, pois, como afirma Calligaris, adolescentes estão no lugar onde todos os indivíduos gostariam de estar neste século XXI. Têm a obrigação de ser felizes, ou pelo menos deveriam fazer de conta: "Se a adolescência é um ideal para todos, ele só pode ter a delicadeza de ser feliz". E conclui: "Em nossa cultura, a passagem para a vida adulta é um verdadeiro enigma" ${ }^{45}$.

"Feliz" e sozinho, vivendo numa situação de margem e sem ninguém ao seu lado para fazer a "travessia", adolescentes estão no lugar onde todos gostariam de estar. E Lipovetsky conclui: "Quando o futuro parece ameaçador e incerto, resta debruçar-se sobre o presente, que não paramos de proteger, arrumar e reciclar, permanecendo em uma juventude sem fim"

Nesse sentido, é possível reafirmar a importância do rito de passagem na vida de adolescentes. No entanto, percebe-se que ritos que faziam sentido já não o fazem mais e necessitariam ser ressignificados para que possam cumprir sua função e seu propósito. Os ritos de passagem nas sociedades ocidentais, nos dias de hoje, não ajudam na inserção no mundo das pessoas adultas, exatamente porque não há clareza em termos de critérios para que se possa afirmar quando se dará essa inserção. A adolescência e sua duração de dez anos ou mais dificultam essa atribuição do rito de passagem nessa fase da vida. Na comunidade religiosa, mesmo quando a inserção está definida por meio da Confirmação, essa efetivamente não acontece em termos de mudança de status e, principalmente, em termos de socialização e de pertencimento a um coletivo, tendo em vista que somente uma parte do grupo continua inserida nas atividades comunitárias, como mostrou a pesquisa com adolescentes, familiares e lideranças comunitárias.

Uma segunda questão diz respeito à realidade de hoje. O transcurso da vida do ser humano e seu desenvolvimento são delimitados em fases ou estágios, ou ainda vistos a partir da ideia de geração, em que os indivíduos são agrupados de acordo com as diferentes faixas etárias. Nessa perspectiva, Machado Pais fala nas "regularidades" que definem e limitam cada fase: "Se existem fases de vida, é porque se encontram sujeitas a regularidades, embora cada indivíduo possa viver singularmente o seu próprio curso de vida" ${ }^{47}$. No entanto, hoje os limites se tornam cada vez mais tênues, dificultando a transição de uma fase da vida para outra: "[...] a repetição ritualista das etapas de vida, característica da tradicional sucessão de gerações, deu lugar a uma

${ }^{45}$ CALLIGARIS, 2009, p. 18.

${ }^{46}$ LIPOVETSKY, 2005, p. 33.

${ }^{47}$ PAIS, 2009, p. 374. 
nova época onde cabe aos indivíduos um papel mais activo na construção das suas trajectórias $[\ldots]^{\prime 48}$.

Lipovetsky vai falar de uma "uma juventude sem fim" e Meira afirma que a ausência de ritos acarreta perdas, principalmente no que tange à socialização, o "voltar-se para o outro, um sentir por intermédio do estar e fazer juntos". E afirma: "Ligada à transição, com sua supressão perde-se o movimento, aquele continuum. Com o alargamento da faixa etária correspondente ao grupo considerados jovens hoje, esse momento transforma-se em um estado, torna-se fixo, duro, prisional" ${ }^{49}$. E assim perde-se o momento da transição, da passagem, da "travessia", que em última instância nem acontece.

Uma nova compreensão dos ritos na adolescência poderia auxiliar nos momentos mais angustiantes dessa "travessia", e por que não, nos momentos de alegria e de conquistas. A função do grupo, o acompanhamento e a orientação das pessoas adultas; e a criatividade para ressignificar os ritos existentes e a constituição de novos ritos podem ser relevantes para a fase da adolescência, e se for levado também em consideração o específico da realidade de hoje.

\section{Referências}

ABERASTURY, A. et al. Adolescência normal. 2. ed. Porto Alegre: Artes Médicas, 1992. CALLIGARIS, Contardo. A adolescência. 2. ed. São Paulo: Publifolha, 2009.

DOLTO, Françoise. A causa dos adolescentes. Aparecida/SP: Idéias \& Letras, 2004.

ERIKSON, Erik. Identidade, Juventude e Crise. Rio de Janeiro: Zahar, 1976.

GENNEP, Arnold van. Os ritos de passagem. Petrópolis: Vozes, 1977.

LIPOVETSKY, Gilles. A era do vazio; ensaios sobre o individualismo contemporâneo. Barueri, SP: Manole, 2005.

MEIRA, Mônica Birchler Vanzella. Sobre estruturas etárias e ritos de passagem. Ponto-e-Vírgula Revista de Ciências Sociais, São Paulo, v. 5, p. 185-201, 1º sem. 2009.

NOSSA fé, nossa vida. Disponível em: $<$ http://www.luteranos.com.br/conteudo/nossa-fe-nossa-vida-a-confirmacao>. Acesso em: 23 set. 2015.

PAIS, José Machado. A juventude como fase de vida: dos ritos de passagem aos ritos de impasse. Saúde Soc. São Paulo, v. 18, n. 3, p. 371-381, 2009.

PALÁCIOS, Jesus. O que é a adolescência. In: COLL, César; PALACIOS, Jesús; MARCHESI, Alvaro (Orgs.). Desenvolvimento psicológico e educação: psicologia evolutiva. Trad. Marcos A. G. Domingues. Porto Alegre: Artes Médicas, 1995. v. 1, p. 263-272.

WACHS, Manfredo Carlos. Confirmação na IECLB: Contribuições para um método. São Leopoldo: Escola Superior de Teologia, 1995.

YIN, Robert K. Estudo de caso: planejamento e métodos. 3. ed. Porto Alegre: Bookman, 2005. YOUNG, Pauline V.; SCHMID, C. Métodos cientificos de investigación social: introducción a los fundamentos, contenido, método, principios y análisis de las investigaciones sociales. 2. ed. México, 1960.

48 MORTIMER; SHANAHAN, 2006 apud PAIS, 2009, p. 374.

49 MEIRA, 2009, p. 199. 